\section{P08.26 THE IMPACT OF EDUCATION ON AUSTRALIAN PRACTICE NURSES' KNOWLEDGE AND ATTITUDES IN RELATION TO CHLAMYDIA TESTING: FINDINGS FROM THE AUSTRALIAN CHLAMYDIA CONTROL EFFECTIVENESS PILOT (ACCEPT)}

${ }^{1} \mathrm{R}$ Lorch ${ }^{*},{ }^{1} \mathrm{R}$ Guy, ${ }^{2} \mathrm{M}$ Temple-Smith, ${ }^{3} \mathrm{~A}$ Vaisey, ${ }^{3} \mathrm{~A}$ Wood, ${ }^{1} \mathrm{~B}$ Ford, ${ }^{4} \mathrm{C}$ Murray, ${ }^{4} \mathrm{C}$ Bourne, ${ }^{5} \mathrm{M}$ Hall, ${ }^{3}$ ) Hocking, on behalf of the ACCEPt Consortium. ${ }^{1}$ The Kirby Institute, UNSW Australia, Sydney, NSW, Australia; ${ }^{2}$ Department of General Practice, University of Melbourne, Victoria, Australia; ${ }^{3}$ Centre for Epidemiology and Biostatistics Melbourne School of Population and Global Health, University of Melbourne, Victoria, Australia; ${ }^{4}$ NSW STI Programs Unit, Sydney, NSW, Australia; ${ }^{5}$ Australian Practice Nurses Association, Melbourne, Victoria, Australia

10.1136/sextrans-2015-052270.372

Introduction ACCEPt is a randomised controlled trial of annual chlamydia testing for 16-29 year olds in general practice. Part of the trial examines whether practice nurses (PNs) can play a role in chlamydia testing. PNs previously identified education as an important facilitator to their involvement in testing. We evaluated the impact of education on PNs' knowledge and attitudes in relation to chlamydia testing.

Methods The 2-hour education program was delivered at clinics to PNs by ACCEPt staff. A survey was conducted at baseline and repeated 6-12 months post education; analysis focused on PNs who completed both surveys. The survey used Likert scales, which were analysed as continuous variables (scores). We used ttests to assess if changes in mean scores between survey rounds were greater in the education group.

Results In total 72 PNs completed both surveys (42 of which received education). Changes in mean scores between survey rounds in the education group were significantly different to the non-education group for the statements: most chlamydia infections in men are asymptomatic $(\mathrm{p}=0.01)$; I would offer a chlamydia test to a 23-year old married female having a pap test ( $\mathrm{p}$ $=0.04)$; I would like to be more involved in testing $(\mathrm{p}=0.04)$; I would like to be more involved with managing a recall/ reminder system $(\mathrm{p}=0.05)$; and time/workload constraints are barriers to testing $(\mathrm{p}=0.001)$. The increases in mean knowledge score $(\mathrm{p}<0.01)$ and mean barrier score $(\mathrm{p}=0.03)$ were greater in education group.

Conclusion Our evaluation suggests $\mathrm{PN}$ participation in the ACCEPt education program improved chlamydia testing knowledge and attitudes among PNs and could be utilised more widely across primary care. The findings also suggest time/workload constraints became a stronger barrier after education, presumably due to greater involvement in testing. Future analyses will determine if the education program combined with other initiatives have increased testing rates.

Disclosure of interest statement ACCEPt was commissioned and funded by the Australian Government Department of Health and Ageing. Additional funding has been received from the National Health and Medical Research Council, the Victorian Department of Health and NSW Health.

\section{P08.27 RESULTS OF A 2014 QLD TRIAL OF PHARMACY ACCESSED TESTING FOR CHLAMYDIA TRACHOMATIS VIA RETAIL SELF-TEST URI SWAB POSTAL SPECIMEN KITS}

${ }^{1} \mathrm{~A}$ Priddle*, ${ }^{2} \mathrm{~J}$ Debattista, ${ }^{1} \mathrm{M}$ Hayes, ${ }^{2} \mathrm{P}$ Marshall, ${ }^{3} \mathrm{~N}$ Pouchkareff, ${ }^{3} \mathrm{R}$ Gordon. ${ }^{1}$ The Pharmacy Guild of Australia Queensland Branch, Australia; ${ }^{2}$ Metro North Public Health Unit, Metro North Hospital \& Health Service, Queensland, Australia; ${ }^{3}$ Townsville Sexual Health Services, Queensland, Australia

\subsection{6/sextrans-2015-052270.373}

Background Chlamydia is the most common Sexually Transmissible Infection in Australia, with 23,535 notifications for the first quarter of 2015 , more than half of which occurring in the 15 to 25 age group. More than $80 \%$ of this high risk age group presenting to a general practice at least once annually, however rates of testing are low at $12.5 \%$ for females and $3.7 \%$ for males. International and Australian studies have suggested pharmacy involvement in testing. Piloting access through Australia's 5,450 pharmacies is essential to reduce the incidence and long-term consequences of chlamydia through early detection, treatment of asymptomatic infection and contact tracing.

Method A 9-month pilot of a retail self-test kit through 18 community pharmacies in the Brisbane Metro North region of Queensland. Each kit contained a uri swab, instructions, reply post envelope, pathology bag and form, and information on chlamydia. The consumer indicated preferred option for return of results.

Results Of 109 kits purchased, 39.4\% were returned for processing, with $16.3 \%$ of these returning a reactive result. $18 \%$ of returned samples were purchased by consumers under the age of 18, 53.5\% between $18-29$ year and the remainder aged over 30 years. All reactive results were subsequently treated.

Conclusion This presentation will discuss integrating community pharmacy into any comprehensive Australian chlamydia testing program. Pharmacies are already providers of sexual health products, including contraception, pregnancy tests and Emergency Hormonal Contraception (EHC), where approximately 400,000 units of EHC provided each year. They are well placed for access to Chlamydia testing over extended hours, providing an additional confidential option access Chlamydia testing with the capacity to increase sexual health awareness and de-stigmatise chlamydia screening.

Disclosure of interest statement This pilot was a collaboration of the Pharmacy Guild of Australia QLD Branch and Metro North Hospital and Health Service, funded by Metro North Brisbane Medicare Local.

\section{P08.28 PATIENTS CONTINUE TO ENGAGE IN RISKY SEXUAL BEHAVIOUR IN THE TIME PERIOD BETWEEN BEING TESTED FOR CHLAMYDIA AND RECEIVING TEST RESULT AND TREATMENT}

${ }^{1} \mathrm{E}$ Harding-Esch*, ${ }^{1} \mathrm{E}$ Sherrard-Smith, ${ }^{1} \mathrm{SS}$ Fuller, ${ }^{1} \mathrm{~A}$ Harb, ${ }^{1} \mathrm{M}$ Furegato, ${ }^{2} \mathrm{C}$ Mercer, ${ }^{3}$ ST Sadiq, ${ }^{4} R$ Howell-Jones, ${ }^{1} A$ Nardone, ${ }^{1} P J$ White, ${ }^{5} \mathrm{P}$ Gates, ${ }^{6} \mathrm{~A}$ Pearce, ${ }^{6} \mathrm{~F}$ Keane, ${ }^{7} \mathrm{H}$ Colver, ${ }^{8} \mathrm{~A}$ Nori, ${ }^{9} \mathrm{C}$ Dewsnap, ${ }^{9} \mathrm{R}$ Schatzberger, ${ }^{10} \mathrm{C}$ Estcourt, ${ }^{10} \mathrm{~S}$ Dakshina, ${ }^{1} \mathrm{CM}$ Lowndes. ${ }^{1}$ Public Health England, London, UK; ${ }^{2}$ University College London, London, UK; ${ }^{3}$ St George's, University of London, London, UK; ${ }^{4}$ Oxford School of Public Health, Oxford, UK; ${ }^{5}$ Royal Cornwall Hospital NHS Trust, Cornwall, UK; ${ }^{6}$ Cornwall Sexual Health Service RCHT Clinic Team, Cornwall, UK; ' University Hospitals of Leicester NHS Trust, Leicester, UK; ${ }^{8}$ St George's Healthcare NHS Trust, London, UK; ${ }^{9}$ Sheffield Teaching Hospitals NHS Trust, Sheffield, UK; ${ }^{10}$ Barts Health NHS Trust, London, UK

10.1136/sextrans-2015-052270.374 
Introduction There is a lack of data on the sexual behaviour of patients between being tested for chlamydia, receiving the test result, and being treated. This time-period may be important in the transmission of chlamydia, as infection could continue to be spread to sexual partners whilst awaiting the test result and treatment.

We aimed to investigate the sexual behaviours of patients in this time-period in order to investigate the benefits a point-ofcare test (POCT) might bring to clinical practice.

Methods A cross-sectional clinical audit of Genito-Urinary Medicine (GUM) clinic attendees in England. Clinic staff conducted a notes review of patients returning for chlamydia treatment following a positive chlamydia test result, and of age- and sexmatched chlamydia negatives attending for initial consultation. Initial consultation data were available for all patients; data on behaviour between test and treatment were available only for chlamydia-positives. The data also served as a sexual history taking audit for the GUM clinics, following British Association of Sexual Health and HIV (BASHH) guidelines.

Results Five of nine GUM clinics approached participated (JulyDecember 2014). The sexual history BASHH auditable outcomes completion rates varied from $0-100 \%$. 775 patients (442 females, 353 males) were included in analyses. Males with 2-4 partners, and those who reported never using a condom, were more likely to be chlamydia positive. For 21/143 (14.7\%) positive patients who provided data, last new sexual contact was in the period between test and treatment.

Conclusion The BASHH 97\% data recording target was only consistently met for one of six auditable outcomes, indicating required improvements in sexual history recording by GUM clinics.

Patients continue to form new sexual partnerships whilst awaiting chlamydia test results, allowing for the possibility of infecting new sexual partners. POCTs which remove the test to treatment delay could prevent this onward transmission.

\section{P08.29 WEB-TOOL TO ASSESS THE COST-EFFECTIVENESS OF CHLAMYDIA POINT-OF-CARE TESTS AT THE LOCAL LEVEL}

${ }^{1} \mathrm{E}$ Harding-Esch*, ${ }^{1,2} \mathrm{E}$ Sherrard-Smith, ${ }^{1,2} \mathrm{C}$ Dangerfield, ${ }^{1} \mathrm{YH}$ Choi, ${ }^{2} \mathrm{~N}$ Green, ${ }^{1,3} \mathrm{M}$ Jit, ${ }^{4} \mathrm{RD}$ Marshall, ${ }^{5} \mathrm{C}$ Mercer, ${ }^{1} \mathrm{~A}$ Nardone, ${ }^{6} \mathrm{R}$ Howell-Jones, ${ }^{7} \mathrm{OA}$ Johnson, ${ }^{8} \mathrm{~J}$ Clarkson, ${ }^{9} \mathrm{~J}$ Wolstenholme, ${ }^{9} \mathrm{CP}$ Price, ${ }^{10} \mathrm{CA}$ Gaydos, ${ }^{11} \mathrm{ST}$ Sadiq, ${ }^{1,2 \mathrm{PJ}}$ White, ${ }^{1,3} \mathrm{CM}$ Lowndes. ${ }^{1}$ Public Health England, London, UK; ${ }^{2}$ Imperial College London, London, UK; ${ }^{4} X$-Lab Limited, Leeds, UK: ${ }^{5}$ University College London, London, UK; ${ }^{6}$ Oxford School of Public Health, Oxford, UK; ${ }^{7}$ University of Leeds, Leeds, UK; ${ }^{8}$ Atlas Genetics Ltd, Trowbridge, UK; ${ }^{9}$ University of Oxford, Oxford, UK; ${ }^{10}$ Johns Hopkins University, Baltimore, USA; ${ }^{11}$ St George's, University of London, London, UK; ${ }^{3}$ London School of Hygiene and Tropical Medicine, London, UK

\subsection{6/sextrans-2015-052270.375}

Introduction Point-of-care tests (POCTs) can eliminate the delay between being tested for chlamydia and receiving the result and treatment, potentially reducing loss to follow-up. However, the cost-effectiveness of POCT implementation depends on multiple factors, including cost-per-test, clinic time, sensitivity and specificity, and the epidemiological impact of POC testing on transmission.

Decision-makers consider a complex range of information when determining potential impact of introducing a POCT. To enable commissioners, providers, POCT manufacturers and others to assess the advantages, disadvantages and uncertainty of POCTs for chlamydia in different local settings, we developed a user-friendly web-based tool (POCTiC): www.poctic.uk.net
Methods The web-tool is underpinned by a transmissiondynamic model for chlamydia, which uses behavioural and prevalence data from the National Survey of Sexual Attitudes and Lifestyle (Natsal), and reproduces local coverage and diagnosis rates from Public Health England datasets. A user group consisting of industry, sexual health facilitators, sexual health commissioners, clinicians, public health experts, and healthcare consultants, provided input throughout. The model is pre-run, but certain variables (e.g. costs) are user-determined.

Results Users can estimate changes in the number of infections and diagnoses occurring under different scenarios, with uncertainty ranges. This allows total costs, and cost per infection averted, to be calculated, while accommodating the considerable variation in chlamydia testing coverage, positivity, and diagnosis rates observed at the local level across England. The epidemiological impact of POC testing is dependent on both test performance characteristics and assumptions about the implementation of the test across local services.

Conclusion This tool enables the uncertainties surrounding chlamydia epidemiology and screening implementation to be explored. It also complements local and national knowledge, and contributes to local-level management of chlamydia infection. Users can use the tool to determine the epidemiological impact and cost-effectiveness of implementing POCTs in a particular setting.

Disclosure of interest statement This work was funded by Innovate UK. Additional thanks are given to the UK Medical Research Council, the National Institute for Health Research and the Electronic Self-Testing Instruments for Sexually Transmitted Infection $\left(\mathrm{eSTI}^{2}\right)$ Consortium funded under the UKCRC Translational Infection Research (TIR) Initiative supported by the Medical Research Council (Grant Number G0901608). The funding sources had no involvement in the study design or conduct; the collection, analysis and interpretation of data; the preparation, review or approval of the manuscript; or the decision to submit the manuscript for publication. The views expressed are those of the authors and not necessarily those of the NHS, the NIHR, the Department of Health, or Public Health England.

CED was employed for part of the project by the National Chlamydia Screening Programme. Atlas Genetics Ltd. develop POCTs for STIs. EHE, CL, STS and CAG have received funding from Atlas Genetics Ltd. for performance evaluations of STI POCTs.

The other authors declare no competing interests.

\section{P08.30 CHLAMYDIA TESTS ORDERED, BUT NOT UNDERTAKEN: SOCIO-DEMOGRAPHIC AND STRUCTURAL BARRIERS IN GENERAL PRACTICE}

${ }^{1} \mathrm{~A}$ Lau*, ${ }^{2} \mathrm{~S}$ Spark, ${ }^{3}$ J Tomnay, ${ }^{4} \mathrm{M}$ Temple-Smith, ${ }^{5,6} \mathrm{CK}$ Fairley, ${ }^{7} \mathrm{R}$ Guy, ${ }^{7} \mathrm{~B}$ Donovan, 'JS Hocking, on behalf of the ACCEPt Consortium. 'Centre for Epidemiology and Biostatistics, Melbourne School of Population and Global Health, University of Melbourne; ${ }^{2}$ School of Public Health and Preventive Medicine, Monash University; ${ }^{3}$ Centre for Excellence in Rural Sexual Health, University of Melbourne; ${ }^{4}$ Department of General Practice, University of Melbourne; ${ }^{5}$ Melbourne Sexual Health Centre; ${ }^{6}$ Central Clinical School, Monash University; ${ }^{7}$ Kirby Institute, University of New South UK

\subsection{6/sextrans-2015-052270.376}

Introduction Chlamydia screening at general practice clinics involves a general practitioner (GP) ordering a test and the patient providing a sample on-site or at a pathology collection centre off site. This study investigated the socio-demographic 